\title{
DESENVOLVIMENTO MORAL NO ADULTO E A EDUCAÇÃO A DISTÂNCIA
}

\author{
Andréa Bonetti Gallego. Doutoranda em Educação PPG/EDU - UFRGS \\ E-mail: andgallego@terra.com.br \\ Tania Beatriz Iwaszko Marques Professora de Psicologia da Educação FACED/UFRGS. \\ E-mail: taniabimarques@ bol.com.br
}

\section{Resumo:}

Este artigo é o resultado de uma pesquisa sobre o desenvolvimento moral em adultos, a partir da relação com tutores e professores na educação a distância. Utilizando a teoria de Piaget e o método de estudo de caso, foram entrevistados com questionários escritos, alunos de um curso de pedagogia. A partir de suas conceituações e reflexões sobre plágio, mapeou-se a evolução no conceito de autoria, investigando, um possível crescimento em termos de desenvolvimento moral através da relação com professores e tutores. Os resultados indicam que relações de cooperação que auxiliem a construção de novos valores possibilitam aos alunos respeitar a produção intelectual do outro, construindo o conceito de plágio e autoria. Assim, relações de cooperação com a equipe docente a distância, podem ser relevantes para o desenvolvimento moral dos alunos.

Palavras-chave: educação a distância; plágio; desenvolvimento moral; relação professor e aluno.

\begin{abstract}
:
This paper outcome from research on moral development in adults, as result of their relationship with tutors and teachers at distance education. Using Piaget's theory and method of case study, pedagogy course students were interviewed using written questionnaires. Based on his concepts and thoughts on plagiarism, evolution in the concept of authorship was mapped out, investigating a possible growth in terms of moral development through the relationship with teachers and tutors. The results indicate that cooperative relationships that help to build new values enable students to respect the intellectual output of another, building the concept of plagiarism and authorship. Thus, cooperation with the teaching staff at distance education may be relevant to the moral development of students.
\end{abstract}

Keywords: Distance education; plagiary; moral development; teacher-student relationship.

\section{Introdução:}

Este artigo é resultado de uma pesquisa sobre as possibilidades de desenvolvimento moral em adultos a partir da relação com tutores e professores a distância, realizada no curso de especialização em tutoria do PPG/Edu - UFRGS ${ }^{1}$. O estudo sobre desenvolvimento moral já vem sendo desenvolvido pelas autoras, enfocando as possibilidades de desenvolvimento moral em jovens e adultos a partir da relação com o professor, aqui ampliada também à figura do tutor.

\footnotetext{
${ }^{1}$ Programa de pós-graduação em educação da Universidade Federal do Rio Grande do Sul.
} 
Neste trabalho são utilizadas as opiniões dos alunos sobre a questão da autoria, ou do plágio, e as alterações de suas opiniões sobre o tema, ao longo do curso, como possível indicador de desenvolvimento moral ao longo da graduação através da relação com os tutores e professores. A abordagem se dá através das conceituações e reflexões sobre a questão do plágio nos alunos pesquisados, tentando mapear, através das suas manifestações de descentração e de reflexão, a evolução no conceito de autoria, investigando, a partir daí, um possível crescimento em termos de desenvolvimento moral na relação com professores e tutores.

Tais dados de pesquisa são relacionados à teoria de Piaget e de pesquisadores da Epistemologia Genética sobre desenvolvimento moral, que partem da premissa que pode ocorrer desenvolvimento moral a partir de relações de cooperação e de respeito mútuo entre jovens e adultos e que a escola ou o meio acadêmico podem ser frutíferos nesse sentido.

\section{A construção do objeto de estudo}

A pesquisa que resultou neste artigo foi realizada em um dos pólos do curso de pedagogia modalidade a distância da UFRGS. Foi aplicado um questionário aberto em 44 alunos em uma de suas aulas presenciais. Apesar de tratar-se de um curso em sua quase totalidade não presencial se optou pela aplicação neste encontro para preservar o anonimato dos sujeitos.

Os alunos em questão são professores que possuem, em sua maioria, formação de nível médio e trabalham em escolas estaduais e municipais. Eles estão cursando sua primeira graduação e trabalham, em sua quase totalidade, em sala de aula, 40 ou 60 horas semanais.

O curso de graduação a distância ocorre em $80 \%$ do tempo de modo não presencial, sendo que os trabalhos propostos pelos docentes do curso de pedagogia, com exceção de uma atividade final do semestre, comum a todas as disciplinas em conjunto, ocorrem a distância. As atividades solicitadas aos alunos são trabalhos, de pesquisa bibliográfica, reflexão sobre leituras e práticas, além da participação em fóruns, onde ocorre interação entre o grupo de alunos, professores e tutores.

Ao longo do curso se observou que o conceito de autoria foi se construindo de modo mais efetivo pelos alunos. No princípio os casos de cópias de trabalhos de outros autores, sem as devidas referências, era algo comum. Com o tempo, muitos alunos passam a demonstrar uma efetiva preocupação com a questão, nos dois sentidos. Ou seja, preocupam-se com as referências em seus trabalhos, com procurar criar algo verdadeiramente seu, assim como passam a buscar que a autoria de seus textos seja respeitada.

A questão do plágio é abordada no curso de modo interdisciplinar, ou seja, assim como eles têm essa questão trabalhada em disciplinas específicas, a questão da autoria é questionada, em todas as disciplinas, sempre que um professor ou tutor se vê frente a situações que remetam a ela. Esta pesquisa parte do pressuposto que respeitar a autoria do outro não é algo que possa ser somente ensinado, mas que isso deve se construir como um valor para o sujeito para que ele passe a respeitá-la.

O problema desta pesquisa foi delimitado, então, da seguinte forma: há possibilidade de desenvolvimento moral em jovens e adultos a partir da relação com professores e tutores a distância?

Através da evolução da conceitualização de autoria dos alunos se busca investigar se ocorre desenvolvimento e em que medida isto ocorre. A questão do plágio 
foi eleita para esta investigação por se tratar de uma manifestação bastante aparente dos valores dos sujeitos.

A pesquisa e a posterior escrita deste artigo se justificam tendo como objetivo buscar dados, através do questionamento a alunos de um curso de graduação a distância, sobre as alterações em seu conceito de plágio, o que apontaria para uma evolução em termos de desenvolvimento moral a partir da relação de cooperação com os tutores e professores. Tutor e professor serão colocados na mesma categoria neste trabalho, em função das falas dos alunos refletirem essa categorização.

$\mathrm{Na}$ atualidade, muitos cursos de graduação a distância buscam a formação de profissionais através unicamente da realização de tarefas, e da "passagem dos conteúdos", de modo que não se privilegia, ou mesmo não é possível, a interação professor aluno.

A idéia aqui é demonstrar, a partir das reflexões surgidas a partir das falas dos alunos, o quanto a relação de interação entre alunos e tutores pode colaborar para o desenvolvimento moral dos alunos, aqui abordada através da questão da autoria, colaborando assim para a idéia da relevância desse tipo de estrutura de ensino.

\section{Desenvolvimento moral no adulto e educação a distância:}

\subsection{O desenvolvimento moral para Piaget}

A obra de Piaget sobre o desenvolvimento do conhecimento, ou Epistemologia Genética, pode ser dividida em teoria cognitiva, moral e social. Aqui abordaremos brevemente a questão do desenvolvimento moral. Freitas (2003) afirma que se trata de um mesmo indivíduo, de uma forma de conceber o sujeito e de como este se relaciona com o mundo. Desse modo podemos afirmar que a construção moral segue o mesmo caminho da construção cognitiva.

O desenvolvimento da moral é abordado por Piaget predominantemente em sua obra O Juízo Moral na Criança (1932) em que ele se refere à evolução da moral na criança, à noção de justiça e ao papel do outro nesse processo. A moralidade na criança se estabelece junto ao seu desenvolvimento cognitivo. É um processo que se inicia no princípio da vida do sujeito, começando com a anomia, passando pela moral da heteronomia e podendo chegar à moral da autonomia. No princípio há um sujeito egocêntrico, que, ao longo dessa evolução, pode se tornar capaz de exercer uma moral da ética e da cooperação, o que não quer dizer que ele necessariamente assim o fará.

A criança, para Piaget, nasce egocêntrica, o que significa simultaneamente, indiferenciação do eu com o mundo exterior e falta de cooperação, constituindo um único fenômeno. O egocentrismo é, desse modo, algo que se opõe à noção de cooperação, não sendo algo exclusivo da criança pequena. Piaget afirma que o egocentrismo ressurge sempre que há necessidade de estruturar novos domínios de conhecimento, assim como quando é necessário estruturá-lo sobre um novo plano, o que ocorre, inclusive, no pensamento científico.

A criança, partindo da relação afetiva com os pais e de respeito por eles e deles por ela, toma seus valores como corretos e adota-os como lei. Quando a criança amplia seu círculo de relações, passando a conviver com outras crianças ou mesmo supondo os pais como iguais, passa a questionar seus valores, a caminho da moral da cooperação.

O conceito de cooperação de Piaget, de acordo com Montangero e MauriceNaville (1998), funda-se na equidade, como uma forma ideal de relações entre indivíduos; implica o respeito mútuo, o princípio de reciprocidade e a liberdade ou a 
autonomia de pessoas em interação. A cooperação é uma forma de equilíbrio, na qual o todo e as partes conservam-se mutuamente. É ideal no sentido de limite para cuja direção tendem as relações humanas livres de toda pressão exterior. Essa forma de interação, do ponto de vista intelectual, se opõe ao egocentrismo, que limita o indivíduo a seu próprio ponto de vista; no plano das relações sociais, opõe-se à coação ou à unidirecionalidade.

A moral da autonomia desenvolve-se a partir da relação com os iguais ou com aqueles que a criança ou adolescente supõe como tais. A relação com os pares é a mais importante nesta constituição, para Piaget. $\mathrm{O}$ autor entende que é sinal de que a criança está chegando à autonomia, o momento em que ela descobre que a verdade é necessária nas relações de simpatia e de respeito mútuos. A reciprocidade é fator de autonomia.

Assim, há autonomia moral quando a consciência considera como necessário um ideal, independentemente de qualquer pressão exterior. Enquanto não havia relação com outrem, não havia necessidade de uma moral: o indivíduo como tal conhecia apenas a anomia. Toda relação com outrem na qual intervenha o respeito unilateral conduz à heteronomia. "A autonomia só aparece com a reciprocidade, quando o respeito mútuo é bastante forte, para que o indivíduo experimente interiormente a necessidade de tratar os outros como gostaria de ser tratado" (Piaget, 1932/1977:172).

Dessa forma, o papel do outro é extremamente importante nesse processo, pois é também a partir da relação com as outras pessoas que a moralidade se constrói. Quando a criança é bem pequena, é através da relação com seus pais (através do respeito por esses adultos) que surge o "aparecimento de uma concepção anunciadora da noção de verdade, o pensamento da criança deixa de afirmar simplesmente o que lhe agrada, para se conformar com a opinião do ambiente" (Piaget, 1932/1977:347). Aqui inicia a coação intelectual de um superior sobre um inferior, que vem a dar origem à moral da heteronomia. Para a criança, essa passagem da satisfação direta de seu prazer, característica da anomia, à busca da satisfação do adulto é uma evolução, pois ela está saindo do egocentrismo inicial e progredindo no caminho da busca por um bem comum.

Em uma etapa posterior, a relação com o outro é também muito importante, pois a entrada do sujeito na moral da autonomia é possibilitada, além, é claro, dos fatores cognitivos, pela confrontação de seus valores com os de outras pessoas, que ele supõe semelhantes e com quem estabelece uma relação de respeito mútuo. Desse modo, há, no desenvolvimento do ser humano, um processo construtivo que explica o surgimento do raciocínio lógico, junto a um processo evolutivo que "nos permite compreender como a partir do mundo amoral da criança pequena surge o homem que age eticamente" (Freitas, 2003:110). Freitas na mesma obra, entende que, para Piaget, todo homem pode tornar-se capaz de ação moral, e são as trocas sociais que permitem que esse processo evolutivo ocorra.

O processo de desenvolvimento moral para Piaget, em uma palavra, é algo que inicia no nascimento e pode ir até o último dia da vida de uma pessoa, desde que não ocorram dificuldades neurológicas. Esse desenvolvimento moral depende, assim como o desenvolvimento cognitivo, para Piaget, dos seus chamados quatro fatores interdependentes do desenvolvimento: maturação, experiência (empírica e lógicomatemática), transmissão social e equilibração. Assim, Piaget (1932) destaca a ação do sujeito sobre o ambiente social, afirmando que as trocas sociais são diferentes ao longo da vida do indivíduo, em que os estádios cognitivos e as etapas morais sucedem-se de forma solidária. Aqui vamos destacar em especial a relação com a figura do tutor ou professor. 


\subsection{Possibilidades de desenvolvimento moral através da relação professor/tutor e aluno}

Para a Epistemologia Genética, a educação escolar pode ser um dos meios que auxilia no desenvolvimento tanto cognitivo quanto moral do sujeito. Ela é algo que vai muito além de uma forma de transmissão dos conhecimentos criados pela humanidade, mas é principalmente um meio em que o sujeito pode agir para construir seu conhecimento. Essa ação, diferentemente do que supõe o senso comum, não se resume à manipulação de objetos, mas é a interação com o meio, destacando que para Piaget o meio não é só as coisas que nos rodeiam, mas, também, as pessoas com quem nos relacionamos.

Piaget (1965/1972) afirma que classicamente educar era adaptar o sujeito ao meio social, ou seja, transformar a constituição psicológica em função de realidades coletivas, às quais a consciência atribui valor. Educar é levar o indivíduo em crescimento em direção a valores sociais, morais e intelectuais. Para ele, no entanto, ao se considerar o sujeito dotado de uma atividade verdadeira e se o desenvolvimento for compreendido de forma dinâmica, a relação entre educando e sociedade se torna recíproca.

O trabalho do professor é destacado como importante para o desenvolvimento do sujeito, de acordo com a Epistemologia Genética. Parrat-Dayan e Tryphon (1998) afirmam que Piaget reflete sobre a pedagogia ao longo de toda sua obra, a qual concentra o aprendizado na criança, mas mantém a importância da função do professor. Para elas, Piaget concorda com a Escola Nova e seus métodos no que se refere à importância que esta dá aos princípios de liberdade, de atividade e de interesse da criança. Desse modo, ele entende que, se a educação deve favorecer a autonomia, o ensino baseado unicamente na transmissão oral e na autoridade deve ser abolido. No entanto, para Piaget, o papel do professor difere, mas não deixa de existir.

As autoras entendem que, para Piaget, o papel do professor é o de propiciar que se desenvolva no espírito da criança uma ferramenta que lhe permita compreender o mundo, instrumento que se funda na reciprocidade e na cooperação e que permite à criança escapar do egocentrismo. O professor é, assim, um colaborador indispensável à classe. Ele fornece informações, mas não impõe verdades, incentiva o aluno a se propor questões e a tornar-se um experimentador ativo. Ele deve propor um grande número de situações e experiências ao aluno. Ainda segundo Parrat-Dayan e Tryphon (1998), para a concepção piagetiana de pedagogia, é preciso que o professor crie instrumentos que permitam ao aluno compreender o mundo. A fala das autoras é relevante para este trabalho, apesar de tratar especificamente do ensino da criança, se compreendemos como Piaget que a construção do conhecimento se dá seguindo os mesmos mecanismos ao longo da vida de uma pessoa.

Para Araújo (1999), o professor que obtém o respeito e a admiração do aluno pelo prestígio e pela competência de seus conhecimentos e que consegue estabelecer relações de respeito mútuo tem uma verdadeira autoridade, pela qual o único medo do aluno é perder o respeito da pessoa de que gosta. "Esse professor ou professora consegue estabelecer relações baseadas no diálogo, na confiança e nutrir uma afetividade que permite que os conflitos cotidianos da escola sejam solucionados de maneira democrática" (Araújo, 1999:42).

Becker (1993:10) afirma que em uma pedagogia centrada na relação os papéis do professor e do aluno na escola tendem a ser des-absolutizados: "o professor traz sua bagagem, o aluno também. São bagagens diferenciadas que entram na relação. Nada a 
rigor pode ser definido previamente". O interessante é que sejam negados o autoritarismo do professor e do aluno, resgatando, assim, os dois pólos da relação. Ainda para o autor, em qualquer situação em que haja interação social pode haver aprendizagem, mas ressalta que nem todas as situações são iguais sob este ponto de vista. Sua forma de realização ótima ocorre em um ambiente de liberdade e no qual há lugar para a ação espontânea.

Piaget (1933/1998) ressalta a importância da relação pessoal entre o professor e o aluno em especial para o desenvolvimento da moral, como algo que deve ser transversal a toda disciplina escolar. Para ele, a educação é um todo, não podendo haver divisórias para a inteligência ou para a moral. É importante destacar que para o autor as trocas mais significativas são as que ocorrem com os pares. No entanto, um adulto ou figura de autoridade como um professor pode se colocar no patamar do aluno, estabelecendo relações de reciprocidade e de respeito mútuo, que podem ser relevantes ao desenvolvimento moral.

Aqui podemos pensar que o tutor, mesmo os alunos da graduação os referindo como professores, podem facilitar esse processo, por estar em um patamar intermediário em termos de hierarquia, se aproximando mais da figura de um par.

\section{Metodologia:}

A pesquisa que originou este artigo tem caráter qualitativo e foi feita através do método de estudo de caso. O estudo de caso, de acordo com Yin (2001), é uma estratégia de pesquisa interessante para examinar fenômenos contemporâneos, em função de sua ampla capacidade de lidar com uma variedade de evidências. Para Yin, o estudo de caso é uma investigação empírica que trabalha um fenômeno contemporâneo, dentro de seu contexto na vida real. O estudo de caso, em sua concepção, trabalha com questões explanatórias do tipo "como" ou "por que".

Neste trabalho, tem-se um estudo de caso múltiplo, pois foca mais de um sujeito, mas permanecendo dentro da mesma estrutura metodológica. Para Yin (2001), o caso múltiplo é interessante devido a suas provas resultantes serem mais convincentes.

Para esta pesquisa, segue-se a lógica da replicação, o que é muito diferente da lógica da amostragem que serve para se avaliar a incidência de um fenômeno. Na lógica da replicação, buscam-se resultados semelhantes, ou contrastantes apenas por razões previsíveis em termos teóricos, permitindo um resultado total convincente, sem a utilização de um número muito grande de sujeitos.

O caso aqui trabalhado é composto por uma turma de alunos do curso de pedagogia a distância, que tem por característica ser formada por alunos adultos, professores, com formação média. Com a análise das afirmações de cada aluno verificam-se suas idéias a respeito das alterações em sua conceituação de plágio ao longo do curso. Após essa etapa, foi possível reunir as informações trazidas por cada indivíduo em uma análise conjunta, criando uma hipótese sobre a ocorrência de desenvolvimento moral através da interação entre alunos e tutores na educação a distância. 
O instrumento utilizado neste trabalho é um questionário escrito, composto de perguntas abertas. Posteriormente as respostas dos alunos foram apresentadas em categorias. Como se trata de perguntas abertas, foram estabelecidas categorias de análise em que os tipos de resposta mais característicos foram agrupados em função de sua semelhança, e explicitados junto a uma resposta que caracteriza a idéia central das falas ali representadas.

A aplicação do questionário ocorreu no intervalo de uma aula presencial da disciplina em que trabalho como tutora, no segundo semestre de 2009. Primeiramente os objetivos da pesquisa foram longamente explicitados aos alunos, sendo esclarecido também que a participação seria anônima e voluntária. Todos os alunos do pólo concordaram em participar. Os questionários foram aplicados em 44 alunos do sétimo semestre do curso de pedagogia a distância.

O questionário iniciava com a contextualização do tema e com uma historinha sobre uma aluna que copiava um trabalho na Internet, e logo pedia que os alunos refletissem sobre o tema, se colocando no lugar da aluna e de sua professora. Logo, o questionário trazia as cinco questões, que proporcionaram os dados para esta pesquisa: hoje?

1. A sua opinião sobre plágio, quando iniciaste a graduação, era a mesma de

2. O que mudou?

3. Por que motivos tu entendes que mudou?

4. Tu achas que a relação com algum professor ou tutor colaborou para essa mudança? De que forma? que forma?

5. Tu achas que a relação com algum colega colaborou para essa mudança? De

\section{Resultados alcançados:}

As respostas às perguntas dos questionários foram agrupadas em categorias por semelhanças. Para cada pergunta há uma tabela específica, aqui acompanhada de sua análise. A tabela 1 contém as respostas da totalidade dos 44 alunos pesquisados, e as tabelas seguintes trabalham somente com os argumentos dos 30 alunos que entendem que sua opinião sobre plágio se alterou ao longo da graduação em curso.

Tabela 1 - Levantamento das respostas da primeira pergunta do questionário

\begin{tabular}{|l|l|l|}
\hline $\begin{array}{l}\text { A sua opinião sobre plágio, quando } \\
\text { iniciaste a graduação, era a mesma de }\end{array}$ & 14 & Não \\
hoje?
\end{tabular}

Dos 44 alunos que responderam ao questionário, 30, ou seja, mais que a metade dos alunos, entende que seu conceito ou sua forma de ver o plágio se alterou durante a graduação.

Tabela 2 - Levantamento das respostas da segunda questão

O que mudou?

Passei a conhecer o conceito de plágio, que é ilegal.

06 


\begin{tabular}{|l|l|}
\hline Passei a achar importante fazer referências completas. & 06 \\
\hline Passei a refletir sobre a ética. & 03 \\
\hline Aprendi que posso ser punido. & 02 \\
\hline $\begin{array}{l}\text { Passei a acreditar que consigo realizar atividade } \\
\text { sozinho. }\end{array}$ & 06 \\
\hline Não respondeu. & 07 \\
\hline
\end{tabular}

A tabela dois traz um dado bastante interessante. Seis alunos entendem que sua mudança ocorreu a título de informação e dois por medo de punição. Essas alterações são relevantes por ser uma caminhada no processo, mas ainda estão muito presas à moral da heteronomia. No entanto, nove alunos demonstram alteração em termos de valores e de reflexão ética. Seis alunos também referem diferença em termos de processo de aprendizagem, ao referir que passaram a acreditar que são capazes de fazer atividade sozinhos.

Tabela 3 - Relação das respostas para a terceira questão

\begin{tabular}{|l|l|}
\hline Por que motivos tu entendes que mudou? & \\
\hline $\begin{array}{c}\text { Porque agora posto na Internet e não gosto / não quero } \\
\text { que copiem o meu. }\end{array}$ & 04 \\
\hline Porque hoje sei como devemos fazer uma citação. & 03 \\
\hline Porque eu achava que se estava na rede era público. & 03 \\
\hline $\begin{array}{l}\text { Porque passei a me preocupar com o tema, achar } \\
\text { importante. }\end{array}$ & 06 \\
\hline Porque tenho medo da punição. & 03 \\
\hline De tanto os tutores falarem. & 02 \\
\hline $\begin{array}{l}\text { Porque passei a me preocupar com minha } \\
\text { aprendizagem. }\end{array}$ & 04 \\
\hline Não respondeu. & 07 \\
\hline
\end{tabular}

Essa tabela é interessante não só pelos dados que apresenta, como pela semelhança de respostas com a tabela anterior. Ela nos traz seis alunos afirmando que mudaram a partir do momento que passaram a se preocupar com a questão, onde podemos supor que mudaram através da reflexão.

Sobre o elenco de motivos, aparecem também declarações bastante egocêntricas, quando quatro alunos referem que sua opinião mudou porque não querem que copiem o seu. No entanto, mesmo sobre essa já podemos supor um movimento de pensamento sobre a questão, que poderia levar o aluno a se colocar no lugar do autor.

Aparecem também seis repostas no sentido do esclarecimento. Três alunos referem uma posição bastante heterônoma de medo da punição, sendo que quatro referem que mudaram devido à preocupação com sua aprendizagem.

Quatro referem a insistência do tutor, resposta ambígua que tanto pode nos fazer pensar em uma abertura para o diálogo autônomo, quanto na obediência heterônoma.

Tabela 4 - Levantamento das respostas dadas para quarta questão

Tu achas que a relação com algum professor ou tutor colaborou para 
essa mudança? De que forma?

Porque a tutora fica chamando a atenção, cobrando.

O diálogo virtual constante favorece a reflexão e a troca de saberes

Dicas dos tutores, esclarecimento.

Nos mostraram que não precisamos copiar.

Não respondeu.

06

07

07

01

09

Esta tabela é muito importante, pois se refere especificamente à percepção dos alunos sobre a influência da relação com um tutor ou professor para essa mudança. Dos 30 alunos que acreditam que algo mudou, 23 entendem que a relação com professores ou tutores auxiliou nesse processo. Desses, seis referem mudanças filiadas à moral da heteronomia, ou seja, falam que mudaram por terem sido cobrados, pela figura de autoridade.

Sete alunos afirmam que conversas virtuais constantes favoreceram a reflexão e a troca de saberes, o que pode ser um indicador de desenvolvimento moral, no sentido de uma relação de cooperação e de respeito mútuo que os leva a pensar de modo diferente sobre o que é certo ou errado.

Sete alunos também afirmam que mudaram em função de dicas dos tutores, o que pode ser tomado como simples esclarecimento, mas que pode ser compreendido, também, como uma relação de cooperação que leva a uma mudança de valores.

Um aluno volta a referir aqui também a questão cognitiva, de passar a se sentir capaz de realizar o trabalho acadêmico.

Tabela 5 - Relação das respostas para a quinta questão

\begin{tabular}{|l|l|}
\hline $\begin{array}{l}\text { Tu achas que a relação com algum colega colaborou para essa } \\
\text { mudança? De que forma? }\end{array}$ & \\
\hline O diálogo virtual constante favorece a reflexão e a troca de saberes. & 04 \\
\hline Me assustei como resultado das cópias dos colegas, medo da & 02 \\
punição. & 02 \\
\hline Sim, porque fiquei braba quando copiaram o meu. & 04 \\
\hline Me chamam atenção para o fato. & 01 \\
\hline Me incentivam a fazer o meu, falam que eu posso. & 18 \\
\hline Não respondeu. & \\
\hline
\end{tabular}

Esta tabela demonstra que muitos alunos ainda valorizam pouco a troca com os pares, refletindo certa postura de relação com a autoridade, mais típica da heteronomia, onde as regras são rígidas e vêm de cima. Isso fica claro quando 18 de 30 entendem que as conversas com colegas não são relevantes. Mesmo assim, nove alunos deram respostas que refletem relações de cooperação com os pares e supõem crescimento em função delas.

\section{Conclusão}

Ao longo do período do curso de pedagogia a distância da UFRG pudemos observar a questão do plágio como algo constante nas conversas com os alunos. A informação sobre o tema foi algo trabalhado com os alunos pelos professores de 
seminário integrador ${ }^{2}, \operatorname{logo}$ no início do curso. Essa questão vem sendo abordada de modo interdisciplinar desde lá, ou seja, tutores e professores independentemente de sua área específica trabalham com a questão sempre que ela aparece, não somente no sentido de apontar possíveis dificuldades, como através da discussão sobre autoria do material que se encontra em sites da Internet, como sobre os trabalhos dos próprios alunos.

No decorrer do curso, ao lidar diariamente com a produção escrita dos alunos, pudemos observar que muitos alunos passaram a agir de modo mais ético em relação a suas produções, no entanto esse é um tema recorrente e algumas dificuldades ainda são encontradas. A questão, aqui, é entender, através da fala dos alunos, se essa mudança ocorreu e principalmente compreender como ela ocorreu. Isso se justifica, pois a parte informativa da questão ocorreu do mesmo modo para todos, mas os alunos demonstram movimentos diversos sobre essa construção. Se entendermos, como afirma Piaget, que aprendizagem se dá através da interação entre o sujeito e o objeto do conhecimento, que aqui se refere aos trabalhos escritos e prioritariamente a relação com tutores, é relevante buscar de que modo isso ocorreu e porquê. A partir da análise da fala dos alunos se evidencia, como afirma a teoria de Piaget, que a relação com os professores e tutores auxiliou no processo de construção do conceito de plágio.

Muitos alunos, mais que compreender o que significa o termo, passaram a considerar a propriedade intelectual como um valor. Aqui podemos observar um movimento de descentração, quando os alunos passam a se colocar no lugar do autor, pensando como se sentiriam ao serem copiados.

Um dado relevante também são as afirmações no sentido de o quanto a troca com professores e tutores auxilia os alunos a construírem sua identidade como autores, e eles afirmam passar a acreditar que podem escrever e que seu texto tem valor. Ainda sobre a construção do conhecimento emergem falas sobre passar a acreditar que o aprendizado é algo importante, o que não necessariamente era evidente a princípio.

Em termos de desenvolvimento moral poderia se entender que esses alunos tiveram a oportunidade, através das relações de cooperação com os tutores e professores, de construir novos valores, permitindo-lhes respeitar a produção intelectual do outro. O plágio passa a ser reconhecido como tal por esses alunos, agora mais autônomos. Assim, podemos concluir que relações de cooperação com a equipe docente, no meio acadêmico a distância, podem ser relevantes para o desenvolvimento moral dos alunos.

\section{Referências bibliográficas:}

ARAÚJO, Ulisses Ferreira. Respeito e autoridade na escola. In: AQUINO, Júlio Groppa. Autoridade e autonomia na escola: alternativas teóricas e práticas. São Paulo: Sumus, 1999.

BECKER, Fernando. A epistemologia do professor: o cotidiano na escola. Petrópolis: Vozes, 1993.

FREITAS, Lia. A moral na obra de Jean Piaget: um projeto inacabado. São Paulo: Cortez, 2003.

${ }^{2}$ Disciplina que tem a função integrar as aprendizagens dos alunos ao longo do curso. 
GALLEGO, Andréa Bonetti. Adolescência e moralidade: o professor que faz a diferença. Porto Alegre: Faculdade de Educação, Universidade Federal do Rio Grande do Sul, 2006. Dissertação de Mestrado.

MONTANGERO, Jaques; MAURICE-NAVILLE, Danielle. Piaget ou a inteligência em evolução. Porto Alegre: Artes Médicas, 1998.

PARRAT-DAYAN; TRYPHON. Sobre a pedagogia: Textos inéditos. São Paulo: Casa do psicólogo, 1998. P.97-113. (ed. org. 1933).

PIAGET, Jean. O juízo moral na criança. São Paulo: Mestre Jou, 1977. (ed.org. 1932).

PIAGET, Jean. Psicologia e pedagogia. Rio de Janeiro: Forense, 1972. (ed. org. 19351965).

YIN, Robert K. Estudo de Caso: planejamento e métodos. Porto Alegre: Bookman, 2001 . 